www.jmscr.igmpublication.org Impact Factor 5.244

Index Copernicus Value: 83.27 ISSN (e)-2347-176x ISSN (p) 2455-0450 crossref DOI: _http://dx.doi.org/10.18535/jmscr/v4i8.51

\title{
A Study on Relation between Posterior Missing Teeth and Temperomandibular Disorders
}

\author{
Authors \\ R.Prithi, D.Pradeep \\ Saveetha Dental College
}

\section{ABSTRACT}

AIM: The purpose of this study is to investigate whether the number of missing posterior teeth are associated with TMD.

BACKGROUND: Loss of posterior teeth, especially when the number of missing teeth is small, may exert secondary changes, including drifting and tipping of the remaining teeth. The former is the medial or distal movement of a tooth through a stable alveolar ridge, and the latter is the movement from a line perpendicular to the alveolar segment. The result of drifting and tipping is the exhibition of secondary changes in occlusal contact, called 'tightly locked occlusion'. This could have an effect on TMJ.

METHOD AND MATERIAL: This study was conducted at Saveetha Dental College and Hospitals, Chennai. A sample size of 50 partially edentulous patients were included in the study. A questionnaire was provided to the patients to fill in their personnel details like age, gender, while other clinical details corresponding to the patient was recorded and filled by the investigator.

RESULT: The result in this study is that, out of 50 individuals women were 23 and men were 27 in numbers respectively. Clicking sound were found in $17.39 \%$ and male were $11.1 \%$. Pain was found to be present in $65.2 \%$ females and $40.7 \%$ males. Unilateral chewing preferences was found to be $73.9 \%$ in females and $33.3 \%$ in males, while bilateral preference was found in $26.08 \%$ females and $66.6 \%$ in males. Deviation of mandible was found to be in $47.8 \%$ of females and $37.03 \%$ of males.

CONCLUSION: Symptoms and signs of TMD were associated with loss of posterior teeth among subjects included in the study. The number of subjects who reported TMD symptoms seemed to decrease and those who had TMD signs increased with increasing age.

The number of missing posterior teeth increased with age, and was significantly associated with TMD signs and symptoms. Although more women reported symptoms, posterior teeth loss was associated with TMD signs especially among men.

KEY WORDS: missing posterior teeth, malocclusion, temperomandibular disorder.

\section{INTRODUCTION}

Temporomandibular disorders (TMD) is a collective term that includes a number of clinical complaints involving the muscles of mastication, the temporomandibular joint (TMJ), or the associated orofacial structures. $^{(1)}$ It is characterrized by several signs and symptoms that include facial muscle and joint pain, limitation and / or mandibular deviation in the trajectory, joint noises, headaches, earaches and pain of cervical origin. $^{(2)}$ 
The etiology of TMD is still unknown, however several studies have reported relationships between TMD and bruxism, grinding or clenching of the teeth, osteoarthrosis, abnormal occlusion, ${ }^{(3)}$ tooth wear $^{(4)}$ nonworking-side occlusal interferences, ${ }^{(5)}$ limited mandibular movements, auditory function, menstrual cycle, ${ }^{(6)}$ partial loss of teeth, masseter muscle activity, osteoarthritis, Anxiety and depression and reduced maximum bite force. The etiology of TMD is multifactorial and these include trauma, genetics, anatomical factors and occlusion. the most popular theories regarding TMD etiology are based on the biopsychosocial model, which involves a combination of biological, psychological and social factors. ${ }^{(7,8)}$

\section{METHOD AND MATERIALS}

This study was conducted at Saveetha Dental College and Hospitals, Chennai. A sample size of 50 partially edentulous patients were included in the study, of which women were (23) and men were (27). All partially edentulous patients with all maxillary and mandibular anterior teeth existed; those with two or more missing posterior teeth (premolars and molars) with the exception of third molars were included. Those who had been previously diagnosed and treated as symptomatic TMD patients, removable partial denture-wearing subjects and who were exposed to traumatic loss of teeth (i.e. car accident, gunshot, maxillofacial surgery,...etc.) were excluded from this study.

A questionnaire was provided to the patients to fill in their personnel details like age, gender, while other clinical details corresponding to the patient was recorded and filled by the investigator. The patients personnel information was kept confidential. Clinical examination was performed on patients with their consent to record details like clicking sound, pain, side of chewing preference, number of missing teeth, duration of missing teeth, deviation of mandible and vertical distance.

\section{RESULT}

The study consists of a sample size of 50 partially edentulous individuals of which women were $23(46 \%)$ and men were $27(54 \%)$ in numbers respectively. Individuals from $35-80$ years of age were considered for the study. Clinical intraoral and extraoral examinations were recorded and analysed.

Clicking sound in females were found to be in $4(17.39 \%)$ and male were $3(11.1 \%)$ in number. Pain was found to be present in 15(65.2\%) females and 11(40.7\%) males. Unilateral chewing preferences was found to be in $(73.9 \%)$ of females and $(33.3 \%)$ in males, while bilateral preference was 6 in females and 18 in males. Deviation of mandible was found to be in $(47.8 \%)$ of females and $(37.03 \%)$ of males.

Unilateral missing teeth was recorded in 19 females and 12 males, while bilateral missing was seen in 4 females and 15 males. Duration of missing teeth was categorised among two groups i.e 1-5years and 6-10years. Also another important parameter the vertical distance of the jaw was measured for every patient and was averagely found to be $5.8 \mathrm{~cm}$ in length.

\section{Table 1GENDER}

\begin{tabular}{|l|l|}
\hline GENDER & NO. OF INDIVIDUALS \\
\hline FEMALE & $23(46 \%)$ \\
\hline MALE & $27(54 \%)$ \\
\hline TOTAL & 50 \\
\hline
\end{tabular}

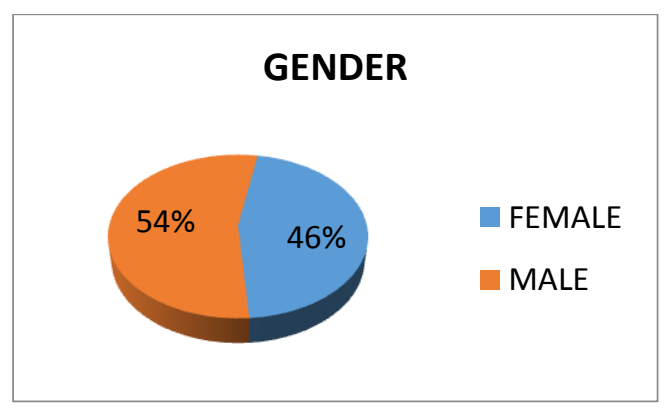

Table 2 SYMPTOMS OF TMD

\begin{tabular}{|l|l|l|}
\hline SYMPTOMS & FEMALE & MALE \\
\hline CLICKING SOUND & $4(17.39 \%)$ & $3(11.1 \%)$ \\
\hline PAIN & $15(65.2 \%)$ & $11(40.7 \%)$ \\
\hline $\begin{array}{l}\text { DEVIATION OF } \\
\text { MANDIBLE }\end{array}$ & $11(47.8 \%)$ & $10(37.03 \%)$ \\
\hline
\end{tabular}




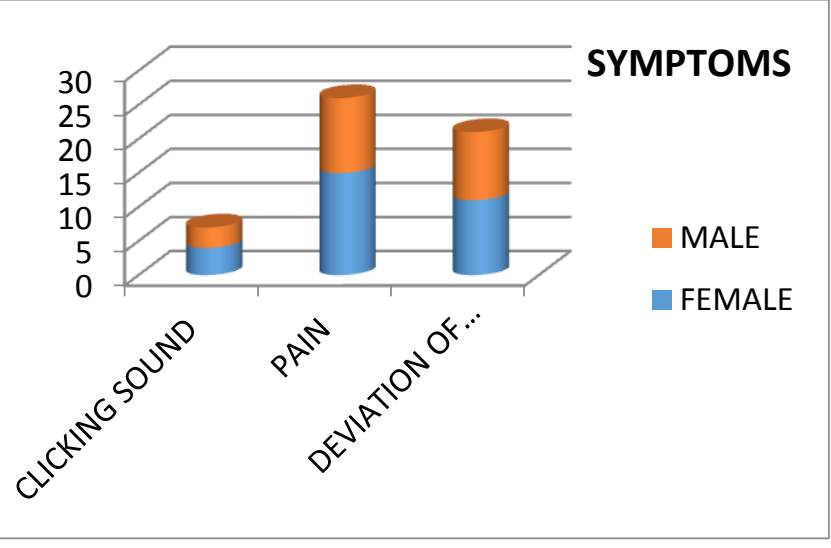

Table 3 SIDE OF CHEWING

\begin{tabular}{|l|l|l|}
\hline SIDE OF CHEWING & FEMALE & MALE \\
\hline UNILATERAL & $17(73.9 \%)$ & $9(33.3 \%)$ \\
\hline BALANCED & $6(26.08 \%)$ & $18(66.6 \%)$ \\
\hline
\end{tabular}

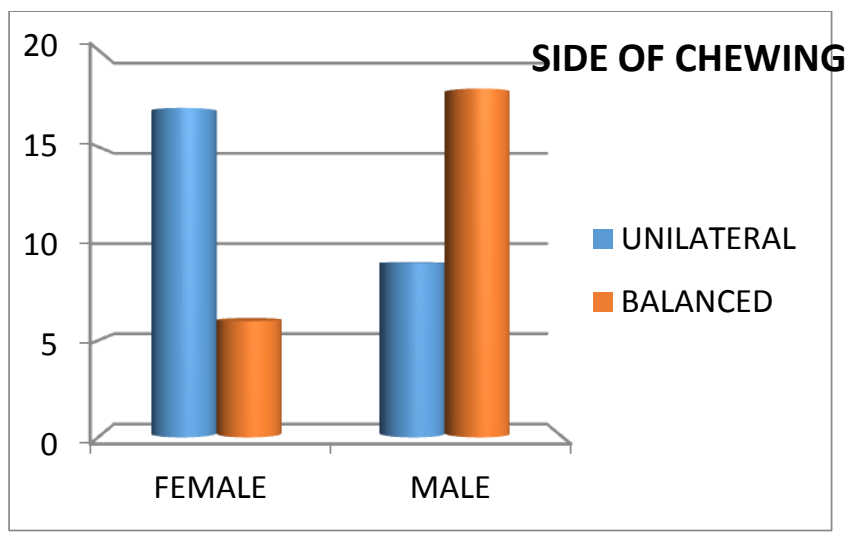

Table 4 MISSING TEETH

\begin{tabular}{|l|l|l|}
\hline MISSING TEETH & FEMALE & MALE \\
\hline UNILATERAL & $19(82.6 \%)$ & $12(44.4 \%)$ \\
\hline BILATERAL & $4(17.3 \%)$ & $15(55.5 \%)$ \\
\hline
\end{tabular}

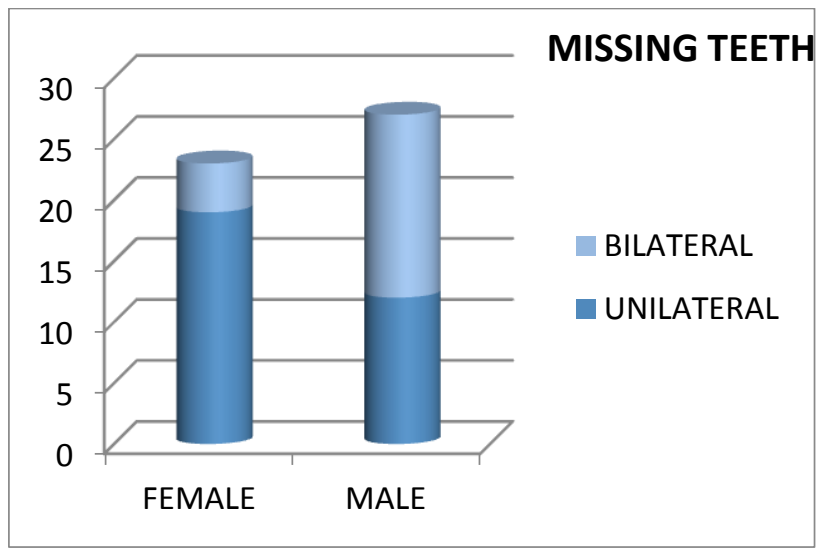

\section{DISCUSSION}

Occlusion influences the dynamic morphological and functional relationships between all components of the masticatory system - the teeth and their supporting tissues but also the neuromuscular system, the temporomandibular joints (TMJs) and the craniofacial skeleton ${ }^{(9,10)}$. Patient comfort and oral functionality depends on vertical dimension of dentition, occlusion, maintenance of hard tissue and temporomandibular joint health. The occlusal instability could be attributed to changes like tooth migration, supraeruption, drifting, tilting of teeth and occlusal wear and often exacerbates in cases of unopposed and lone standing teeth with inadequate periodontal support. ${ }^{(11)}$

A hypothesis supporting the association between posterior teeth and functioning of TMJ was being mentioned. The absence of posterior teeth support results in overloading of the temporomandibular joint (TMJ) structures. It has been assumed and experimentally proved that the absence of posterior teeth would result in mandibular overclosure and as a consequence, the condyles would deviate from their normal centric position in the TMJ, causing dislocation in the joint. Joint pain has also been reported more frequently on the side with most missing teeth and increased risk of joint disorders were found in subjects without any molar support. Correlation between absence of posterior support and osteoarthritis of TMJ was reported in several studies. However, this has been controversial as few other studies have concluded that risk of osteoarthritis of the temporomandibular joint in people without posterior teeth was not different from those with complete dental arches. Missing posterior teeth has been associated with the TMJ sound like clicking. Previous studies have also observed that TMJ sounds may originate from changes in articular surfaces, deviations in the form of articular components and lack of muscle coordination. In another study, it was observed that loss of molar support was involved in the initiation of lesions on the load bearing articular surfaces of the condyle and articular eminence of younger individuals. A recent study examined the relationship between missing mandibular molars and TMJ dysfunction. 
It was concluded from the study that clicking joint sound and condylar flattening of the TMJ was more significant in unilateral loss of molars as compared to bilateral loss. ${ }^{(20)}$

In this study, $54 \%$ of the participants were men amd $46 \%$ were women, although there was no statistically significant difference in the mean age between genders, women were slightly younger than men. This study shows higher percentage of women with TMD symptoms like clicking sound, pain and deviation of mandible due to loss of posterior teeth than their counter part.

Some studies, have reported that women have a greater percentage of problems related to TMD than do men. ${ }^{(12)}$ Several attempts have been made to provide an explanation for this difference, authors have attributed it to hormonal differences, menstrual cycle or to reduced pain threshold in women. ${ }^{(13)}$ The finding that women are more symptomatic and that TMD symptoms decreased with age is well-documented in the dental literature. ${ }^{(14)}$

On the contrary, TMD signs become more prevalent with age. Some investigators have reported that TMD signs encountered in degenerative disease of the articular surfaces, often associated with aging, such as osteoarthrosis, which is present more frequently amongst elderly patients. Moreover, osteoarthritic changes may occur in apparently asymptomatic subjects. ${ }^{(15)}$ This may explain that elderly become less symptomatic although they have already TMD signs.

Although TMD symptoms decreased with age, the signs increased and it seems that an increase of number of posterior teeth loss is associated with TMD signs rather than symptoms. ${ }^{(16)}$ This significant association between TMD signs and tooth loss is in agreement with various clinical and epidemiological studies ${ }^{(17)}$. Dulcic et al. suggested that the incidence and intensity of TMD are higher in subjects with greater tooth loss in the supporting zones, regardless of their sex. Tallents et al. reported that missing mandibular posterior teeth may accelerate the development of degenerative joint disease ${ }^{(18)}$. In contrast, Mundt et al. suggested that the loss of occlusal support was significantly associated with muscle and TMJ tenderness in men only ${ }^{(19)}$.

Restoration of missing natural teeth has been suggested to decrease or eliminate signs and symptoms of TMD. ${ }^{(21)}$. However, no sufficient evidence of an association between TMD and loss of molar teeth, and restoration of missing teeth does not seem to decrease the prevalence of TMD. Malocclusion has been one of the most frequently cited causes of both condylar displacement and masticatory muscle disorders, although this study did not investigate the association of malocclusion with TMD signs and symptoms, further research is still required to study the effect of these variables on TMD.

\section{CONCLUSION}

Symptoms and signs of TMD were associated with loss of posterior teeth among subjects included in the study. The number of subjects who reported TMD symptoms seemed to decrease and those who had TMD signs increased with increasing age.

The number of missing posterior teeth increased with age, and was significantly associated with TMD signs and symptoms. Although more women reported symptoms, posterior teeth loss was associated with TMD signs especially among men.

\section{REFERENCE}

1. Okeson JP, de Leeuw R. Differential diagnosis of temporomandibular disorders and other orofacial pain disorders. Dent Clin N Am 2011; 55:105-120.

2. Pereira JF, Conti PCR. Alteraçõesoclusais e a suarelação com a disfunçãotempormandibular. Rev FacOdontol Bauru. 2001;9(3-4):139-44

3. Pullinger AG, Seligman DA. Quantification and validation of predictive values of occlusalvariables in temporomandibular disorders using a 
multifactorial analysis. J Prosthet Dent 2000; 83:66-75.

4. Carlsson GE. The etiology of temporomandibular disorders. J Orofac Pain 2001; 15:106-108.

5. Carlsson GE, Egermark I, Magnusson T. Predictors of bruxism, other oral parafunctions, and tooth wear over a 20year follow-up period. J Orofac Pain 2003; 17:5057.

6. Isselée H, De Laat A, De Mot B, Lysens R. Pressure-pain threshold variation in temporomandibular disorder myalgia over the course of the menstrual cycle. J Orofac Pain 2002; 16:105-117.

7. Dworkin SF, Massoth DL. Temporomandibular disorders and chronic pain: disease or illness? J Prosthet Dent, 72(1), 1994; 29-38.

8. Engel GL. The need for a new medical model: a challenge for biomedicine. Science, 196(4286), 1977; 129-136

9. McNeill C. Fundamental treatment goals. In: McNeill C, ed. Science and practice of occlusion. Chicago, IL:Quintessence 1997:306-22.

10. Klineberg I, Jagger R. Occlusion and clinical practice -An evidence based approach. Edinburgh: Wright, 2004.

11. Sreedhar C, Baratam S. Deep overbite- A review (Deep bite, Deep overbite, and Excessive overbite). Annals and Essences of Dentistry 2009:8-25.

12. Casanova-Rosado JF, Medina-Solís CE, Vallejos-Sánchez AA, et al. Prevalence and associated factors for temporomandibular disorders in a group of Mexican adolescents and youth adults. Clin Oral Invest 2006; 10:42-49.

13. Botelho AP, Veiga MCF. Influence of sex on temporomandibular disorder pain: a review of occurrence and development. Braz J Oral Sci 2008; 7:1631-1635.
14. Özden AN, Ersoy AE, Kisnisci RS. Clinical aspects of temporomandibular disorders. Turk J Med Sci 2000; 30:77-81.

15. Isselée H, De Laat A, De Mot B, Lysens R. Pressure-pain threshold variation in temporomandibular disorder myalgia over the course of the menstrual cycle. J Orofac Pain 2002; 16:105-117.

16. Sipila K, Napankangas R, Kononen M, et al. The role of dental loss and denture status on clinical signs of temporomandibular disorders. $J$ Oral Rehabil 2013;40:15-23.

17. Al-Jabrah OA, Al-Shumailan YR. Prevalence of temporomandibular disorder signs in patients with complete versus partial dentures. Clin Oral Invest 2006; 10:167-173.

18. Tallents RH, Macher DJ, Kyrkanides S, et al. Prevalence of missing posterior teeth and intraarticular temporomandibular disorders. J Prosthet Dent 2002; 87:45-50.

19. Mundt T, Mack F, Schwahn C, et al. Gender differences in associations between occlusal support and signs of temporomandibular disorders: results of the population-based Study of Health in Pomerania (SHIP). Int $J$ Prosthodont 2005; 18:232-239.

20. Gupta SK, Pratibha PK, Bhat KM,1 Mutalik S, Guddattu V. Non-replaced Mandibular First Molars and Temporomandibular Joint Dysfunction. Nepal Journal of Medical Sciences, 3(1),2014, 58-63.

21. Forssell H, Kalso E. Application of principles of evidence-based medicine to occlusal treatment for temporomandibular disorders: Are there lessons to be learned? J Orofac Pain 2004; 18: 9-22. 